\title{
Produtividade e valor nutricional da parte aérea e de raízes tuberosas de oito genótipos de mandioca de indústria
}

\author{
Yield and nutritional value of shoots and tuberous roots of eight industry cassava \\ genotypes
}

\author{
FERNANDES, Francisco Duarte ${ }^{1^{*}}$; GUIMARÃES JÚNIOR, Roberto ${ }^{1}$; VIEIRA, \\ Eduardo Alano ${ }^{1}$; FIALHO, Josefino de Freitas ${ }^{1}$; MALAQUIAS, Juaci Vitória ${ }^{1}$
}

${ }^{1}$ Embrapa Cerrados, Planaltina, Distrito Federal, Brasil.
${ }^{*}$ Endereço para correspondência: francisco.fernandes@embrapa.br

RESUMO

Neste estudo avaliou-se a produtividade e o valor nutricional, para ruminantes, da parte aérea e das raízes de oito genótipos de mandioca para indústria (BGMC 1304, BGMC 1299, BGMC 1297, BGMC 1262, BGMC 991, BGMC 923, BGMC 788 e BGMC 436), cultivados em área experimental da Embrapa Cerrados no município de Planaltina-DF $\left(15^{\circ}\right.$ $35^{\prime} 30^{\prime \prime}$ de latitude Sul, $47^{\circ} 42^{\prime} 30^{\prime \prime}$ de longitude oeste a $1000 \mathrm{~m}$ de altitude). Aos 12 meses após o plantio, efetuou-se a poda da parte aérea de todos os genótipos. Aos 18 meses após o plantio o experimento foi avaliado, momento em que foram colhidas as partes aéreas e as raízes tuberosas de cada genótipo em cada parcela experimental. O delineamento experimental foi em blocos ao acaso, com três repetições, sendo as médias comparadas pelo teste de Scott-Knott. Houve diferenças significativas entre os genótipos para produtividade de matéria seca (MS) da parte aérea e de raízes, bem como para as características nutricionais, com exceção para potássio, fósforo, magnésio e cobre da parte aérea e digestibilidade in vitro da matéria seca (DIVMS), e, para potássio, fósforo, cálcio e magnésio das raízes. O genótipo BGMC 1304 apresentou maior produtividade de parte aérea $\left(8.554 \mathrm{~kg} \mathrm{ha}^{-1}\right)$ e teores médios de $44,24 \%$ de DIVMS e $12,58 \%$ de proteína bruta (PB) nessa fração da planta. O BGMC 923 se destacou pela maior produtividade de raízes $\left(17.760 \mathrm{~kg} \mathrm{ha}^{-1}\right)$, com DIVMS média de $86,93 \%$ e PB 2,27\%.

Palavras-chave: avaliação nutricional, digestibilidade, minerais, ruminantes

\section{SUMMARY}

In this study we evaluated the yield and nutritional value for ruminants of shoots and roots of eight industry cassava genotypes (BGMC 1304, BGMC 1299, BGMC 1297, BGMC 1262, BGMC 991, BGMC 923, BGMC 788 and BGMC 436), grown at Embrapa Cerrados experimental field in Planaltina-DF (15 ${ }^{\circ} 35^{\prime} 30^{\prime}$ ' south latitude, 4742 ' $30^{\prime}$ ' west longitude at $1000 \mathrm{~m}$ altitude). The shoots of all genotypes were pruned twelve months after planting. Eighteen months after planting shoots and the tuberous roots of each genotype in each plot were harvested. The experimental design was a randomized block with three replications and means were compared by Scott-Knott. There were significant differences among genotypes for shoots and roots dry matter yield (DMI) as well as in terms of nutritional traits, except for potassium, phosphorus, magnesium and copper in shoots and in vitro dry matter digestibility (IVDMD), potassium, calcium and magnesium in roots. The BGMC 1304 showed higher yield of shoots $\left(8,554 \mathrm{~kg} \mathrm{ha}^{-1}\right)$ and mean levels of $44.24 \%$ and $12.58 \%$ for IVDMD and crude protein $(\mathrm{CP})$, respectively. The BGMC 923 stood out for its higher root yield $(17,760 \mathrm{~kg}$ $\mathrm{ha}^{-1}$ ) with averages of $86.93 \%$ IVDMD and $2.27 \% \mathrm{CP}$.

Keywords: digestibility, minerals, nutritional assessment, ruminants 


\section{INTRODUÇÃO}

No Brasil, as pastagens, sobretudo, de gramíneas tropicais, constituem a principal fonte de alimento para os ruminantes. Nestas condições, os níveis desejados de produção só serão obtidos quando a disponibilidade de nutrientes na matéria seca ingerida for capaz de suprir os requerimentos nutricionais dos animais em pastejo. É sabido que, na época seca, período crítico de produção forrageira, a forragem não supre as demandas mínimas dos animais, tanto em função da baixa qualidade, como da quantidade, determinando baixos rendimentos nas atividades pecuárias.

Nesse contexto, se destaca a mandioca que é considerada uma planta de utilização integral na alimentação de várias espécies animais como bovinos, caprinos, ovinos, aves e suínos, especialmente de ruminantes. As raízes são fontes de carboidratos não estruturais, sobretudo amido, que as convertem em fonte de energia e a parte aérea fornece proteínas, concentradas principalmente nas folhas.

Tradicionalmente, por ocasião da colheita das raízes tuberosas, só um quinto da parte aérea da planta de mandioca é aproveitado para a produção de manivas-sementes, empregadas no plantio de novas áreas, sendo o restante, geralmente, desprezado no campo, o que poderia ser utilizado para a produção de produtos de origem animal (NUNES IRMÃO et al., 2008; MOTA, 2011).

Pesquisas têm demonstrado que a parte aérea da mandioca é uma opção possível de ser incluída na formulação de dietas para ruminantes (AZEVEDO et al., 2006; TOMICH et al., 2009; FERREIRA et al., 2011; MOTA et al., 2011; ROCHA NETO et al., 2012; SOUZA et al., 2012). Já Fialho \&
Vieira (2013) mencionam que uma boa estratégia de manejo da cultura na região do Cerrado, para utilização na alimentação animal, principalmente, em lavouras com variedades de mandioca para indústria, é a poda da parte aérea aos 12 meses após o plantio, onde parte da mesma é utilizada como manivassementes, para o novo plantio, e o restante na alimentação animal. No momento da colheita aos 18 meses, estaria disponível nova parte aérea, com alto teor nutritivo para alimentação animal e as raízes para uso na indústria ou mesmo na alimentação animal, como fonte de energia.

Neste sentido, o presente estudo objetivou avaliar a produtividade e o valor nutritivo da parte aérea e de raízes de oito genótipos de mandioca de indústria cultivados na região do Cerrado brasileiro.

\section{MATERIAL E MÉTODOS}

Oito acessos de mandioca de indústria do Banco Regional de Germoplasma de Mandioca do Cerrado (BGMC), sendo: i) dois clones do programa de melhoramento genético de mandioca da Embrapa Mandioca e Fruticultura Tropical (CNPMF) BGMC 991 (clone 3), BGMC 1304 (clone 9661/06), BGMC 1289 (clone 9607/07); ii) duas variedades de mandioca do CNPMF BGMC 1297 (BRS Mani-Branca e BGMC 923 (BRS Formosa); iii) duas variedades do Instituto Agronômico de Campinas BGMC 436 (IAC 12) e BGMC 788 (IAC 14); e a variedade local de Tocantins BGMC 1262 (Enita Brava). Os acessos foram avaliados a campo, em área experimental da Embrapa Cerrados no município de Planaltina-DF entre outubro de 2006 e abril de 2008. 
No período de condução dos experimentos a média das temperaturas máximas diárias foi de $28,23^{\circ} \mathrm{C}$, a média das temperaturas mínimas diárias foi de $16,80^{\circ} \mathrm{C}$, a média das temperaturas médias diárias foi de $21,77^{\circ} \mathrm{C}$, a média da umidade relativa do ar foi de $69,30 \%$, a velocidade média do vento foi de $1,89 \mathrm{~m} \mathrm{seg}^{-1}$, a média de horas de insolação diária foi de 7,33h, a média de radiação diária foi de $19,20 \mathrm{MJ} \mathrm{m}^{-2}$, a precipitações acumulada foi de 1648 $\mathrm{mm}$ e a média de evapotranspiração potencial foi de $4,3 \mathrm{~mm}$.

No local de condução dos experimentos a composição física e química dos solos foi de $43 \%$ de argila, $13 \%$ de silte $44 \%$ de areia, $\mathrm{pH}$ em $\mathrm{H}_{2} \mathrm{O}$ de $5,50, \mathrm{Al}^{+++}$de $0,70 \mathrm{cmolc} \mathrm{dm}^{-3}, \mathrm{Ca}^{++}$de $2,90 \mathrm{cmolc} \mathrm{dm}^{-}$ ${ }^{3}, \mathrm{Mg}^{++}$de $0,50 \mathrm{cmolc} \mathrm{dm}^{-3}, \mathrm{H}+\mathrm{Al} \mathrm{de}$

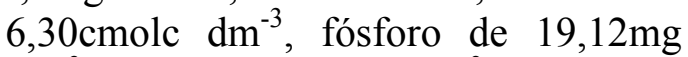
$\mathrm{dm}^{-3}$, potássio de $58 \mathrm{mg} \mathrm{dm}^{-3}$ e $3,56 \%$ de matéria orgânica.

$\mathrm{O}$ delineamento experimental foi o de blocos casualizados com três repetições, sendo cada parcela constituída por 4 linhas de 10 plantas, em espaçamento de $1,20 \mathrm{~m}$ entre linhas e $0,80 \mathrm{~m}$ entre plantas e a área útil foi constituída pelas 16 plantas centrais de cada parcela. Os tratos culturais (adubação e calagem) foram realizados de acordo com as recomendações técnicas da cultura da mandioca para a região do Cerrado (FIALHO et al., 2013, FIALHO \& VIEIRA, 2013) e o controle de plantas daninhas foi realizado por meio de capina.

Aos 12 meses após o plantio, efetuou-se a poda da parte aérea a $10 \mathrm{~cm}$ do solo, de todos os genótipos (nesse momento não foi efetuada nenhuma avaliação). Aos 18 meses após o plantio o experimento foi avaliado, momento em que foram efetuadas as pesagens $\mathrm{e}$ foram obtidas amostras de aproximadamente 400 gramas da parte aérea triturada e homogeneizada e das raízes tuberosas picadas de todos os tratamentos.

As amostras de raízes e da parte aérea foram então identificadas, pesadas e colocadas em estufa com ventilação forçada a $55^{\circ} \mathrm{C}$ para determinação da matéria pré-seca. Após a pré-secagem as amostras foram moídas em moinho Tipo Willey com peneira de $1 \mathrm{~mm}$, em seguida procedeu-se a secagem definitiva em estufa com temperatura de $105^{\circ} \mathrm{C}$ por 16 horas. O conteúdo de proteína bruta foi determinado com base no conteúdo de nitrogênio total, dosado pelo método Kjeldahl, utilizando o fator de conversão para proteína bruta de 6,25. O procedimento seguiu a metodologia descrita por Silva \& Queiroz (2002). As análises de fibra em detergente neutro (FDN) e fibra em detergente ácido (FDA) foram determinadas segundo o método seqüencial proposto por Van Soest et al. (1991). A digestibilidade in vitro da matéria seca (DIVMS) foi determinada pelo método proposto por Tilley \& Terry (1963). As análises dos elementos minerais potássio em porcentagem $(\mathrm{K})$, fósforo em porcentagem $(\mathrm{P})$, cálcio em porcentagem $(\mathrm{Ca})$, magnésio em porcentagem $(\mathrm{Mg})$, enxofre em porcentagem (S) e cobre em $\mathrm{mg} \mathrm{kg}{ }^{-1}$ $\mathrm{Cu}$ foram realizadas por ICP OES com plasma acoplado indutivamente da Thermo scientific. Todas as análises químico-bromatológica foram realizadas no laboratório de Química Analítica de Plantas da Embrapa Cerrados.

Os dados obtidos foram submetidos à análise de variância e as médias dos caracteres foram agrupadas por meio do teste de Scott-Knott, a $(\mathrm{P}<0,05)$. Todas as análises estatísticas foram realizadas com o auxílio do programa estatístico Genes. 


\section{RESULTADOS E DISCUSSÃO}

Os resultados das análises de variância individuais dos parâmetros avaliados na fração da parte área de mandioca aos 18 meses após o plantio revelaram a existência de diferenças significativas $(\mathrm{P}<0,05)$ entre os genótipos quanto a todos os caracteres aferidos, com exceção dos nutrientes fósforo em porcentagem da matéria seca $(\mathrm{P})$, potássio em porcentagem da matéria seca $(\mathrm{K})$, cálcio em porcentagem da matéria seca $(\mathrm{Ca})$, e cobre em $\mathrm{mg} \mathrm{kg}^{-1}$ da matéria seca $(\mathrm{Cu})$ (Tabela 1). Essas diferenças explicitam a importância da avaliação de genótipos de diferentes origens e níveis de melhoramento genético.

Quanto à produtividade de matéria seca da parte aérea (PMS), o genótipo BGMC 1304 se destacou com $8.554 \mathrm{~kg} \mathrm{ha}^{-1}$ $(\mathrm{P}<0,05)$ em relação aos demais genótipos (Tabela 1). Em sequência, os mais produtivos foram BGMC 1297, BGMC 991, BGMC 923, BGMC 788 e BGMC 436, que, por sua vez superaram os genótipos BGMC 1299 e BGMC 1262. Os valores referentes à produtividade são próximos aos citados por Moura \& Costa (2001), que ao avaliarem cinco cultivares de mandioca no Estado do Acre, verificaram produtividades de MS de parte aérea colhida aos cinco meses, variando de 4.000 a $9.000 \mathrm{~kg} \mathrm{ha}^{-1}$. Já Azevedo et al. (2006), no Estado do Rio Grande do Sul, ao avaliarem três variedades de mandioca, colhidas aos seis meses de idade, relataram valores de produtividade de matéria seca da parte aérea, oscilando de 3.240 a $5.870 \mathrm{~kg} \mathrm{ha}^{-1}$. Por outro lado, Tomich et al. (2009), no Estado do Mato Grosso do Sul, ao avaliarem uma cultivar de mandioca, obtiveram resultado de produtividade de matéria seca da parte aérea superior aos obtidos nesse experimento, quando a cultivar foi colhida aos doze meses de idade.

A produtividade da parte aérea da cultura de mandioca depende de algumas variáveis como variedade, idade da planta, espaçamento, adubação e condições edafoclimáticas. A parte aérea da mandioca pode ser uma alternativa para redução dos custos de produção na atividade pecuária, visto que é um subproduto pouco aproveitado pelos produtores rurais. $\mathrm{Na}$ alimentação animal, esse subproduto pode ser utilizado como forragem in natura (fresca) e conservada na forma de feno ou de silagem. Ressaltese, porém, que a parte aérea de mandioca de indústria na forma in natura necessita passar por uma exposição ao sol logo após o corte, para redução do ácido cianídrico a níveis seguros para seu fornecimento aos animais. Geralmente se recomenda um tempo que pode variar de 12 a 24 horas, dependendo da umidade da forragem e das condições climáticas. A sua utilização como feno e/ou silagem, principalmente quando confeccionados com o terço superior da planta, são excelentes volumosos para a alimentação de ruminantes. Os processos de fenação e ensilagem também reduzem as concentrações de ácido cianídrico. A porcentagem matéria seca (MS) da parte aérea diferiu $(\mathrm{P}<0,05)$ entre os genótipos com os maiores valores observados para o BGMC 1297, BGMC 788 e BGMC 436, comparados aos demais genótipos. Os valores oscilaram de 19,23\% (BGMC 991) a $24,47 \%$ (BGMC 788) (Tabela 1). Esses resultados são semelhantes aos obtidos por Ferreira et al. (2009), que, ao avaliarem a parte aérea de mandioca colhidas aos doze meses de idade, observaram teores de MS de 22,10 e $23,35 \%$ e por Silva et al. (2010), avaliando a parte aérea de mandioca colhida aos cinco meses de idade, encontraram teores de MS de 17,00\%. 
Tabela 1. Resumo da análise de variância e comparação de médias determinados na parte aérea de mandioca de indústria avaliada aos dezoito meses após o plantio

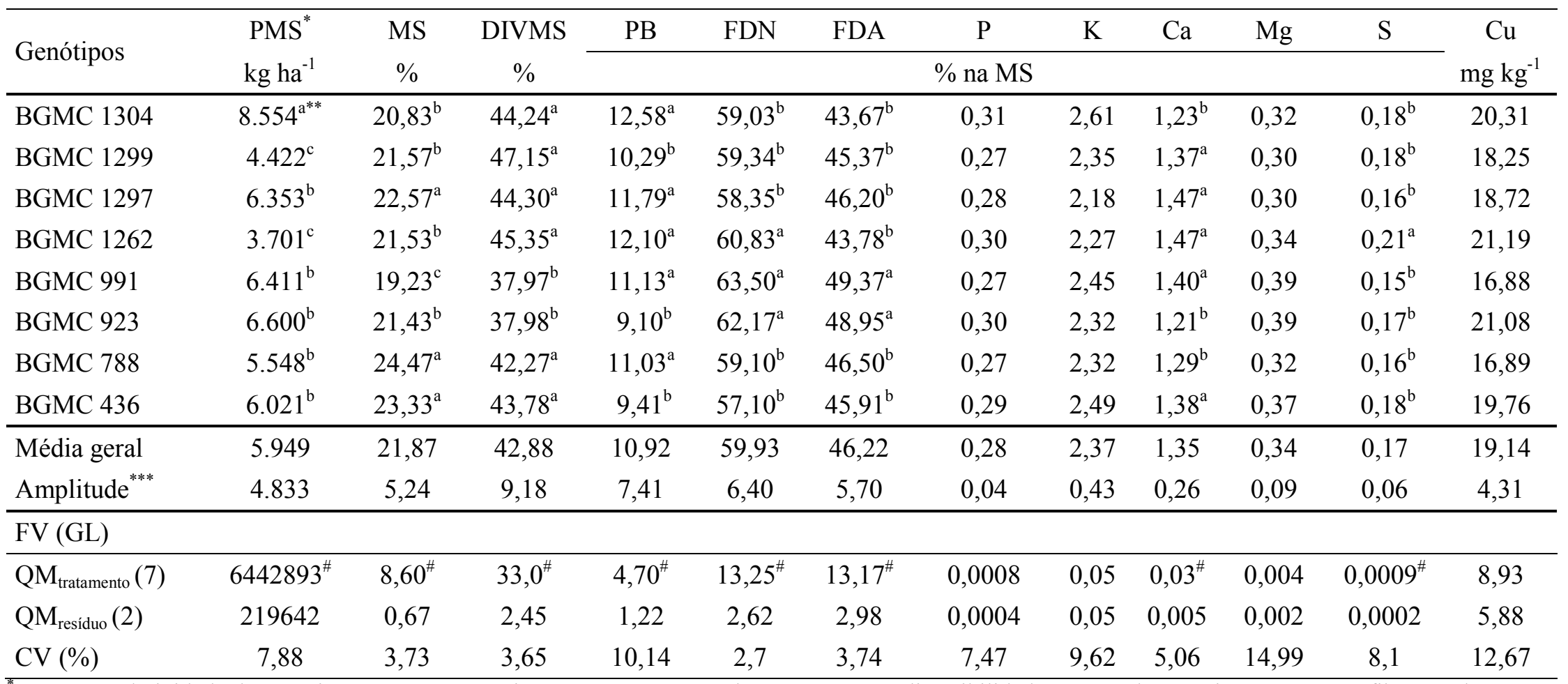

"PMS = Produtividade de matéria seca; MS = matéria seca; $\mathrm{PB}=$ proteína bruta; DIVMS = digestibilidade in vitro da matéria seca; FDN = fibra em detergente neutro;

$\mathrm{FDA}=$ fibra em detergente ácido; $\mathrm{K}=$ potássio; $\mathrm{P}=$ fósforo; $\mathrm{Ca}=$ cálcio; $\mathrm{Mg}=$ magnésio; $\mathrm{S}=$ enxofre; $\mathrm{Cu}=\mathrm{cobre}$.

${ }^{* *}$ Médias seguidas de letras distintas na coluna diferem entre si a 5\% de significância pelo teste de separação de médias de Scott-Knott;

**** Diferença entre a maior e a menor média;

\#Quadrado médio do tratamento seguido por (\#) significativo a 5\% de probabilidade de erro pelo teste $\mathrm{F}$. 
A parte aérea dos genótipos avaliados apresentou valores de MS inferiores ao recomendado para ensilagem, que é próximo de $30 \%$, segundo McDonald et al. (1991). Todavia, vários autores mostraram que embora a forragem fresca tenha apresentado valores de MS inferiores $(17,00$ a 25,68\%) ao recomendado para ensilagem, a parte aérea da mandioca e suas frações proporcionaram silagens com qualidade satisfatória (MODESTO et al., 2004; MODESTO et al., 2008; PINHO et al., 2004; FERREIRA et al., 2009; TOMICH et al., 2009; SILVA et al., 2010; SOUZA et al., 2011), bastando seguir as recomendações gerais para ensilagem.

Os resultados da DIVMS da parte aérea diferiram $(\mathrm{P}<0,05)$ entre os genótipos com os maiores valores observados para os genótipos BGMC 1304, BGMC 1299, BGMC 1297, BGMC 1262, BGMC 788 e BGMC 436 e os menores valores para os genótipos BGMC $991 \mathrm{e}$ BGMC 923. As DIVMS variaram de $47,15 \%$ para o BGMC 1299 a $37,98 \%$ para o BGMC 991 (Tabela 1). Esses resultados foram semelhantes aos obtidos por Ferreira et al. (2009). Valores de DIVMS semelhantes também foram relatados por Azevedo et al. (2006) para a silagem da parte aérea e por Tomich et al. (2009) para o feno da parte aérea. Entretanto, Tomich et al. (2008) encontraram valores superiores de DIVMS (50,1 e 58,3 \%) para a silagem da parte aérea de mandioca. A DIVMS é um importante parâmetro na avaliação do valor nutritivo de alimentos para ruminantes, uma vez que seus resultados possuem alta correlação com as digestibilidade in vivo (TILLEY \& TERRY, 1963). A parte aérea da mandioca é constituída por hastes, pecíolos e folhas em proporções variáveis, sendo as hastes a parte predominante, seguido das folhas $\mathrm{e}$ pecíolos. As hastes apresentam altas concentrações de lignina em sua composição, fator desfavorável por proporcionar uma redução na digestibilidade do alimento (VAN SOEST, 1994). Possivelmente, essa variação na DIVMS entre os acessos, seja decorrente das diferenças entre as frações que compõem a parte aérea dos diferentes genótipos.

Os resultados médios para a $\mathrm{PB}$ da parte aérea revelaram diferenças significativas $(\mathrm{P}<0,05)$ entre os genótipos com maiores valores para os genótipos BGMC 1304, BGMC 1299, BGMC 1297, BGMC 1262, BGMC 991, BGMC 788 e os menores valores para os genótipos 1299, BGMC 923 e BGMC 436. Os valores variaram de $12,58 \%$ para o genótipo BGMC 1304 a 9,10\% para o genótipo BGMC 923 (Tabela 1). Os valores de PB estão de acordo com os relatados por Souza et al. (2011) e por Dantas et al. (2010) para o terço superior da parte aérea. Bem como com os valores relatados por Azevedo et al. (2006) e por Tomich et al. (2008) para a silagem da parte aérea de mandioca. Entretanto, valores superiores de PB foram relatados por Ferreira et al. (2009) e por Silva et al. (2010). É importante ressaltar o elevado teor de PB para a parte aérea dos genótipos, cujo valor médio foi $10,92 \%$. Todos os acessos revelaram valores de $\mathrm{PB}$ da parte aérea superiores a 7,0\%, que, segundo Van Soest (1994), é o nível mínimo para uma efetiva fermentação microbiana no rúmen, contribuindo para melhoria do desempenho animal, na seca, quando as pastagens apresentam baixo teor proteico.

Os resultados para a FDN da parte aérea apresentaram diferenças significativas $(\mathrm{P}<0,05)$ entre os genótipos, com maiores valores para os genótipos BGMC 1262, BGMC 991 e BGMC 923 em relação aos demais genótipos. Os 
teores variaram de $63,50 \%$ para o genótipo BGMC 991 a $57,10 \%$ para o BGMC 436 (57,10\%) (Tabela 1). Os valores de FDN da parte aérea estão de acordo com os encontrados por Dantas et al. (2010). Entretanto, resultados superiores de FDN foram observados por Souza et al. (2011) para a parte aérea da mandioca. Por outro lado, valores inferiores de FDN foram reportados por Ferreira et al. (2009) e Silva et al. (2012a) para a parte aérea da mandioca. O caráter FDN é muito importante, haja vista que representa a fração da forragem que está negativamente correlacionada com $\mathrm{o}$ consumo de MS pelos ruminantes (VAN SOEST, 1994). O excesso de FDN na dieta, frequentemente, limita o consumo voluntário devido aos efeitos físicos dos alimentos exercidos sobre o rúmen e à diminuição da taxa de passagem. Tendo isso em vista, o valor médio de $59,93 \%$ de FDN médio para a parte aérea dos genótipos de mandioca não seria fator limitante ao consumo de matéria seca por ruminantes. Além disso, a parte aérea originária de genótipos com menor valor de FDN apresenta maior potencial de consumo.

Os resultados para a FDA da parte aérea apresentaram diferenças significativas $(\mathrm{P}<0,05)$ entre os genótipos com maiores valores para o BGMC $991 \mathrm{e}$ BGMC 923 em relação aos valores para os demais genótipos. Os teores variaram de 49,37\% para BGMC 991 a 43,67\% para BGMC 1304 (Tabela 1). Os resultados de FDA da parte aérea estão de acordo com os citados por Souza et al. (2011) e por Dantas et al. (2010). Por outro lado, valores inferiores de FDA foram citados por Ferreira et al. (2009) e por Silva et al. (2012a) para a parte aérea da mandioca. A FDA é formada, principalmente, por celulose e lignina, e tem correlação negativa com a digestibilidade da MS da forragem
(VAN SOEST, 1994). Tal característica foi verificada para a parte aérea dos materiais avaliados, uma vez que os que apresentaram as menores concentrações de FDA foram os de maior DIVMS. Assim sendo, a parte aérea originária de genótipos de mandioca com menor valor de FDA apresenta maior potencial de digestibilidade.

Os valores médios de minerais da parte aérea dos genótipos foram de 0,28\% para $\mathrm{P}, 2,37 \%$ para $\mathrm{K}, 1,35 \%$ para $\mathrm{Ca}$, $0,34 \%$ para $\mathrm{Mg}, 0,17 \%$ para $\mathrm{S}$ e 19,14 $\mathrm{mg} \mathrm{k}^{-1}$ para $\mathrm{Cu}$ (Tabela 1). Os genótipos não diferiram estatisticamente quanto às concentrações de $\mathrm{K}, \mathrm{P}, \mathrm{Mg}$ e $\mathrm{Cu}$ da parte aérea. Os genótipos BGMC 1304, BGMC 923 e BGMC 788 apresentaram os menores valores de $\mathrm{Ca}(\mathrm{P}<0,05)$ e o genótipo BGM C 1262 o maior valor de $S \quad(P<0,05)$ na parte aérea, quando comparado aos demais genótipos (Tabela 1). Valores semelhantes foram encontrados por Parry et al. (2005) de $1,89 \%$ para $\mathrm{K}, 1,18 \%$ para $\mathrm{Ca}, 0,36 \%$ para $\mathrm{Mg}$ e $0,19 \%$ para $\mathrm{S}$ na parte aérea de mandioca.

Os resultados das análises de variância dos parâmetros avaliados nas raízes tuberosas de mandioca revelaram a existência de diferenças significativas $(\mathrm{P}<0,05)$ quanto a todos os caracteres aferidos, com exceção do caráter digestibilidade in vitro da matéria seca em porcentagem (DIVMS) e dos nutrientes fósforo em porcentagem da matéria seca $(\mathrm{P})$, potássio em porcentagem da matéria seca $(\mathrm{K})$, cálcio em porcentagem da matéria seca $(\mathrm{Ca}) \mathrm{e}$ magnésio em porcentagem da matéria seca $(\mathrm{Mg})$ (Tabela 2). O que indica que existem diferenças na composição nutricional das raízes dos genótipos avaliados o que justifica a necessidade de se estudar diferentes genótipos a fim da obtenção de estimativas mais seguras dos referidos parâmetros. 
Tabela 2. Resumo da análise de variância e comparação de médias determinados em raízes de reserva de mandioca de indústria avaliadas aos dezoito meses após o plantio

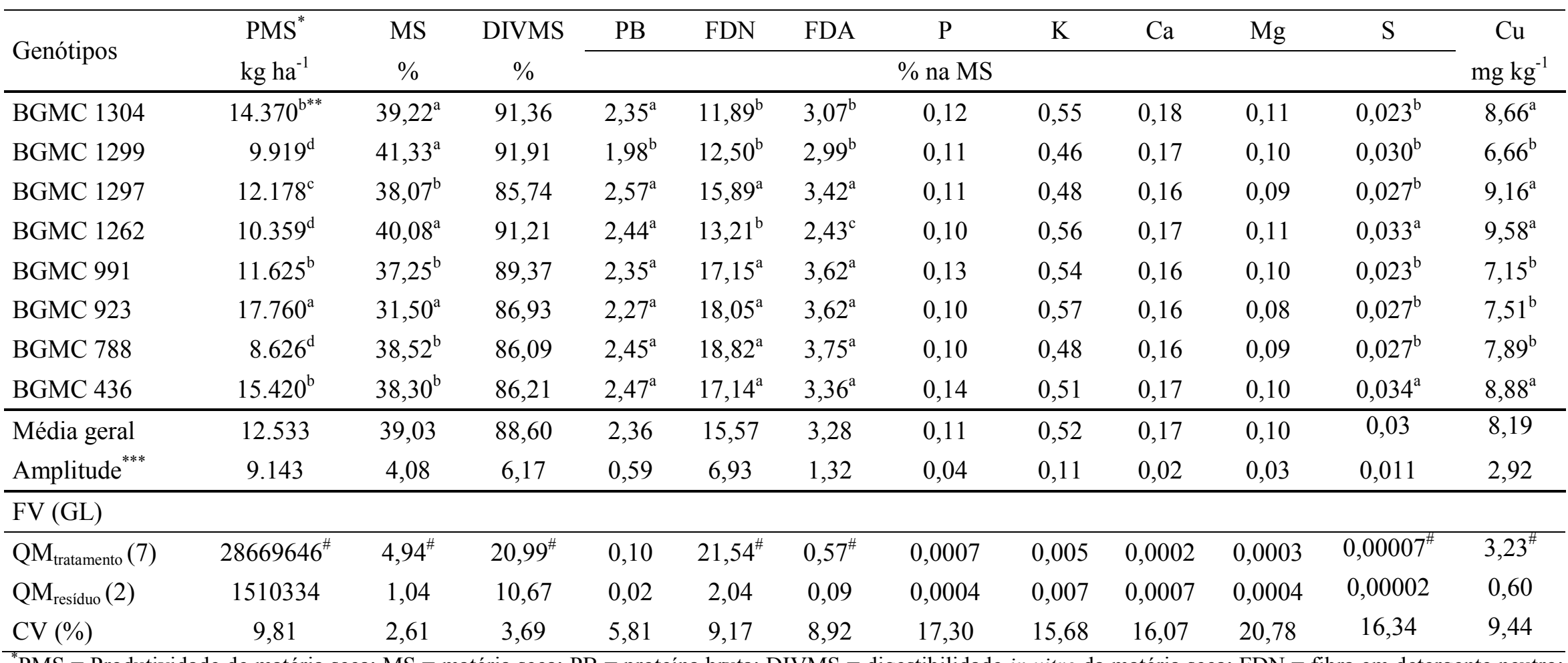

"PMS = Produtividade de matéria seca; $\mathrm{MS}=$ matéria seca; $\mathrm{PB}=$ proteína bruta; DIVMS = digestibilidade in vitro da matéria seca; FDN = fibra em detergente neutro;

$\mathrm{FDA}$ = fibra em detergente ácido; $\mathrm{K}=$ potássio; $\mathrm{P}=$ fósforo; $\mathrm{Ca}=$ cálcio; $\mathrm{Mg}=$ magnésio; $\mathrm{S}=$ enxofre; $\mathrm{Cu}=$ cobre.

${ }^{* *}$ Médias seguidas de letras distintas na coluna diferem entre si a 5\% de significância pelo teste de separação de médias de Scott e Knott;

*** Diferença entre a maior e a menor média;

${ }^{\#}$ Quadrado médio do tratamento seguido por (\#) significativo a 5\% de probabilidade de erro pelo teste F. 
A produtividade média de matéria seca (PMS) das raízes foi de $12.533 \mathrm{~kg} \mathrm{ha}^{-1}$, variando de 8.626 a $17.769 \mathrm{~kg} \mathrm{ha}^{-1}$ (Tabela 2). O genótipo BGMC 923 apresentou PMS de raízes superior $(\mathrm{P}<0,05)$, aos demais genótipos, seguido dos genótipos BGMC 1304 e BGMC 436 que não diferiram $(\mathrm{P}>0,05)$ entre si. Os genótipos BGMC 1297 e BGMC 991 revelaram valores intermediários e os demais genótipos apresentaram menores PMS de raízes. Resultados semelhantes foram reportados por Aguiar et al. (2011), os quais verificaram valores de 8.740 a $17.7900 \mathrm{~kg} \mathrm{ha}^{-1}$ de PMS de raízes. A PMS das raízes é importante por informar o quanto da produtividade total de raízes poderá ser utilizada na alimentação animal. Ou seja, quanto maior a PMS maior a quantidade de ração obtida após a secagem das raízes.

As porcentagens de MS nas raízes foram superiores $(\mathrm{P}<0,05)$ para os genótipos BGMC 1304, BGMC 1299, BGMC 1262 e BGMC 923, em relação aos outros genótipos. Os valores de MS estão dentro da faixa de variação relatada na literatura, de 31,0 a 41,42\% (DANTAS et al., 2010; AGUIAR et al., 2011). Entretanto, em estudo realizado por Oliveira et al. (2010) verificou-se valores inferiores de MS das raízes, mantendo-se entre 28,7 e $29,6 \%$. A MS das raízes é importante pelo fato de determinar o potencial produtivo de matéria seca de um genótipo quando analisada em conjunto com a produtividade de raízes.

Os valores de digestibilidade in vitro da matéria seca (DIVMS) das raízes não foram diferentes estatisticamente entre os genótipos $(\mathrm{P}>0,05)$, variando de 85,74 a $91,91 \%$, com média de $88,60 \%$ (Tabela 2). Os valores de DIVMS foram inferiores ao citado por Oliveira (2008), de $99,0 \%$, ao avaliarem o farelo de raízes. O parâmetro é importante por estar relacionado com o valor energético do alimento.
Os valores de proteína bruta $(\mathrm{PB})$ das raízes foram, em média, 2,36\%, variando de 1,98 a 2,57\%. Excetuando o genótipo BGMC 1299, que apresentou o menor valor de proteína bruta $(\mathrm{PB})$, diferindo estatisticamente $(\mathrm{P}<0,05)$, os outros genótipos apresentaram valores de $\mathrm{PB}$ superiores a 2,0\%. Os valores de PB estão de acordo com outro trabalho realizado sobre a composição química da raiz de mandioca (SILVA et al., 2012b). Verifica-se que a raiz é pobre em proteína e por isso necessita de complementação já que a proteína é diretamente responsável pelo desempenho do animal. Assim, uma alternativa visando aumentar o valor proteico de rações contendo raiz de mandioca seria aproveitar também a parte aérea da planta, cujo valor médio dos genótipos avaliados foi superior a $10 \%$.

As raízes apresentaram, em média, $15,57 \%$ de fibra em detergente neutro (FDN), variando de 11,89 a $18,82 \%$. Os valores de FDN estão dentro de faixas de variação encontrados na literatura, de 11,3 a 19,1\% (OLIVEIRA, 2008). Porém, foram superiores aos observados por Silva et al. (2012b), que registraram valores de FDN de 6,88\%, para a raiz de mandioca. As raízes apresentaram, em média, 3,28\% de FDA, variando de 2,43 a $3,75 \%$. Os valores de FDA foram inferiores ao valor citado por Silva et al. (2012b), de 4,62\%, para a raiz de mandioca.

As raízes apresentaram, em média, 0,11\% para $\mathrm{P}, 0,52 \%$ para $\mathrm{K}, 0,17 \%$ para $\mathrm{Ca}$, $0,10 \%$ para $\mathrm{Mg}, 0,030 \%$ para $\mathrm{S}$ e $8,19 \mathrm{mg}$ $\mathrm{kg}^{-1}$ para $\mathrm{Cu}$ (Tabela 2). Os genótipos apresentaram diferenças significativas $(\mathrm{P}<0,05)$ em relação aos teores de $\mathrm{S}$ e $\mathrm{Cu}$ das raízes, entretanto, apesar de apresentarem certa variação nos teores de $\mathrm{P}, \mathrm{Ca}, \mathrm{K}$ e $\mathrm{Mg}$ não revelaram diferenças significativas $(\mathrm{P}>0,05)$. Os genótipos BGMC 1299, BGMC 1262 e BGMC 436 apresentaram maiores valores de $\mathrm{S}$ e os genótipos BGMC 1304, BGMC 1297, BGMC 1262 e BGMC 436 maiores 
valores de $\mathrm{Cu}$ nas raízes. Resultados apresentados por Parry et al. (2005) referentes aos níveis de minerais na MS de raízes de mandioca foram de 0,15 a $0,69 \%$ para $\mathrm{K}, 0,05$ a $0,07 \%$ para $\mathrm{P}, 0,29$ a $1,03 \%$ para $\mathrm{Ca}, 0,09$ a $0,43 \%$ para $\mathrm{Mg}$, 0,0 a $0,10 \%$ para $\mathrm{S}$ e 3,6 a $13,1 \mathrm{mg} \mathrm{kg}^{-1}$ para $\mathrm{Cu}$. Os dados referentes aos níveis de $\mathrm{K}$, P e Ca, segundo Rostagno (2005), presentes na raspa integral de mandioca, foram $\quad 0,52 \%, \quad 0,20 \%$ e $\quad 0,09 \%$, respectivamente.

A maior produtividade de parte aérea e maior produtividade de raízes tuberosas, na base seca, foram obtidas nos genótipos BGMC 1304 e BGMC 923, respectivamente. Dentre os genótipos existem variações nos parâmetros avaliados, mas, demonstram o potencial produtivo e o valor nutricional da parte aérea e das raízes para uso na alimentação animal, especialmente ruminantes. Considerando que as variedades de mandioca indicadas para a indústria não podem ser utilizadas na alimentação animal na forma "in natura", a estratégia de poda da mandioca aos 12 meses visando o aproveitamento da mandioca para a produção de manivas-sementes, produção de raízes e produção de parte aérea para alimentação animal é promissora para as condições do Cerrado.

\section{AGRADECIMENTOS}

À Embrapa, à Fundação Banco do Brasil e ao $\mathrm{CNPq}$ pelo apoio financeiro.

\section{REFERÊNCIAS}

AGUIAR, E.B.; BICUDO, S.J.; CURCELLI, F.; FIGUEIREDO, P.G.; CRUZ, S.C.S. Épocas de poda e produtividade da mandioca. Pesquisa Agropecuária Brasileira, v.46, n.11, p.1463-1470, 2011.
AZEVEDO, E.B.; NÖRNBERG, J,L.; KESSLER, J.D.; BRÜNING, G.; DAVID, D.B.; FALKENBERG, J.R.; CHIELLE, Z.G. Silagem da parte aérea de cultivares de mandioca. Ciência Rural, v.36, n.6, p.1902-1908, 2006.

DANTAS, A.G.M.; PAULO, J.L.A.; GUERRA, M.G.; FREITAS, M.O. Análises bromatológicas de onze cultivares de mandioca. Revista Caatinga, v.23, n.3, p.130-136, 2010.

FERREIRA, A.L.; SILVA, A.F.; PEREIRA, L.G.R.; BRAGA, L.G.T.; MORAES, S.A.; ARAÚJO, G.G.L. Produção e valor nutritivo da parte aérea da mandioca, maniçoba e pornuça.

Revista Brasileira de Saúde e Produção Animal [online], v.10, n.1, p.983-990, 2009.

FERREIRA, M.; MACHADO, L.C.; FERREIRA, W.M.; SILVA, J. Parte aérea de diferentes cultivares de mandioca como fonte de fibra para utilização na alimentação animal. Revista Raízes e Amidos Tropicais, v.7, n.1, p.111, 2011.

FIALHO, J.F.; SOUSA, D.M.G.; VIEIRA, E.A. Manejo do solo no cultivo de mandioca. In: FIALHO, J.F.; VIEIRA, E.A. (Eds.). Mandioca no Cerrado: orientações técnicas. 2ed. Planaltina: Embrapa Cerrados, 2013. p.39-60.

FIALHO, J.F.; VIEIRA, E.A. Manejo e tratos culturais da mandioca. In: FIALHO, J.F.; VIEIRA, E.A. (Eds.). Mandioca no Cerrado: orientações técnicas. 2.ed. Planaltina: Embrapa Cerrados, 2013. p.61-88.

McDONALD, P.; HENDERSON, A.R.; HERON, S.J.E. The biochemistry of silage. 2.ed. Marlow: Chalcombe Publications, 1991. 226p. 
MODESTO, E.C., SANTOS, G.T., VILELA, D.; SILVA, D.C.; FAUSTINO, J.O.; DETMANN, E.; ZAMBOM, M.A.; MARQUES, J.A. Caracterização químico - bromatológica da silagem do terço superior da rama de mandioca. Acta Scientiarum. v.26, n.1, p.137-146, 2004.

MODESTO, E.C.; SANTOS, G.T.; ZAMBOM, M.A.; DAMASCENO, J.C.; BRANCO, A.F.; VILELA, D. Consumo, digestibilidade e parâmetros ruminais em vacas gestantes alimentadas com silagem de rama de mandioca. Revista Brasileira de Zootecnia, v.37, n.5, p.944-950, 2008.

MOTA, A.D.S.; ROCHA JÚNIOR, V.R.; SOUZA, A.S. REIS, S.T.; TOMICH, T.R.; CALDEIRA, L.A.; MENEZES, G.C.C.; COSTA, M.D. Perfil de fermentação e perdas na ensilagem de diferentes frações da parte aérea de quatro variedades de mandioca. Revista Brasileira de Zootecnia, v.40, n.7, p.1466-1473, 2011.

MOURA, G.M.; COSTA, N.L. Efeito da freqüência e altura de poda na produtividade de raízes e parte aérea em mandioca. Pesquisa Agropecuária Brasileira, v.36, n.8, p.1053-1059, 2001.

NUNES IRMÃO, J.; FIGUEIREDO, M.P.; PEREIRA, L.G.R.; FERREIRA, J.Q.; RECH, J.L.; OLIVEIRA, B.M. Composição química do feno da parte aérea da mandioca em diferentes idades de corte. Revista Brasileira de Saúde e Produção Animal [online], v.9, n.1, p.158-169, 2008.

OLIVEIRA, A.C. Capim-elefante com e sem emurchecimento, acrescido de farelo de mandioca, na produção de silagem. 2008. 55p. Tese (Doutorado) Universidade Federal de Viçosa, Viçosa.
OLIVEIRA, P.S.; VIANA, A.E.S.; MATSUMOTO, S.N.; CARDOSO JÚNIOR, N.S.; SEDIYAMA, T.; SÃO JOSÉ, A.R. Efeito da poda e de épocas de colheita sobre características agronômicas de mandioca. Acta Scientiarum. Agronomy, v.32, n.1, p.99-108, 2010.

PARRY, M. M.; CARVALHO, J.G.; KATO, M.S. A; VIELHAVER, K. Estado nutricional da mandioca cultivada em diferentes épocas sob cobertura morta e duas adubações.

Revista Ciências Agrárias, v.45, n.43, p, 91-114, 2005.

PINHO, E.Z.; COSTA, C.; ARRIGONI, M.B.; SILVEIRA, A.C.; PADOVANI, C.R.; PINHO, S.Z. Fermentation and nutritive value of silage and hay made from the aerial part of cassava (Manihot esculenta Crantz). Scientia Agricola, v.61, n.4, p.364 -370, 2004.

ROCHA NETO, A.L.; VELOSO, C.M.; SILVA, F.F.; SOUZA, D.R.; COSTA, L.T.; MURTA, R.M.; SILVA, R.R.; SILVA, J.C.P.M.; SOUZA, D.D.; MENESES. M.A. Comportamento ingestivo de vacas em lactação alimentadas com cana-de-açúcar ou feno da parte aérea da mandioca. Arquivo Brasileiro de Medicina Veterinária e Zootecnia, v.64, n.6, p.1629-1638, 2012.

ROSTAGNO, H.S.; ALBINO, L.F.T.; DONZELE, J.L.; GOMES, P.C.; OLIVEIRA, R.F. Tabelas brasileiras para aves e suínos: composição de alimentos e exigências nutricionais. 2.ed. Viçosa: Universidade Federal de Viçosa, 2005. 186p.

SILVA, C.F.P.G.; FIGUEIREDO, M.P.; PEDREIRA, M.S.; BERNARDINO, F.S.; FARIAS, D.H.; AZÊVEDO, J.A.G. Cinética e parâmetros de fermentação ruminal in vitro de silagens de parte aérea e raízes de mandioca. 
Arquivo Brasileiro de Medicina

Veterinária e Zootecnia, v.64, n.6, p.1639-1648, 2012a.

SILVA, M.J.M.S.; CARVALHO, F.F.R.; BATISTA, A.M.V.; GUIM. A.; FONSECA, N.N.N.; COSTA, V.M.S. Utilização da raiz de mandioca sobre a digestibilidade e comportamento ingestivo de cabras Saanen em lactação.

Acta Scientiarum Animal Sciences, v.34, n.4, p.401-408, 2012 b.

SILVA, C.F.P.G.; PEDREIRA, M.S.; FIGUEIREDO, M.P.; BERNARDINO, F.S.; FARIAS, D.H. Qualidade fermentativa e caracterização químico bromatológica de silagens da parte aérea e raízes de mandioca (Manihot esculenta Crantz). Acta Scientiarum Animal Sciences, v.32, n.4, p.401-408, 2010.

SILVA, D.J.; QUEIROZ, A.C. Análise de alimentos: métodos químicos $\mathrm{e}$ biológicos. 3ed. Viçosa: Universidade Federal de Viçosa, 2002, 235p.

SOUZA, A.S.; ROCHA JÚNIOR, V.R.; MOTA, A.D.S.; PALMA, M.N.N.; FRANCO, M.O.; DUTRA, E.S.; SANTOS, C.C.R.; AGUIAR, A.C.R.; OLIVIERA, C.R.; ROCHA, W.J.B. Valor nutricional de frações da parte aérea de quatro variedades de mandioca.

Revista Brasileira de Saúde e Produção Animal [online], v.12, n.2, p.441-455, 2011.

SOUZA, A.S.; ROCHA JÚNIOR, V.R.; MOTA, A.D.S.; ROCHA, W.J.B.; OLIVIERA, C.R.; AGUIAR, A.C.R.; SANTOS, C.C.R.; MENDES, G.A. Potencial forrageiro e valor nutricional do feno de diferentes frações da parte aérea de quatro variedades de mandioca.

Revista Brasileira de Saúde e Produção Animal [online], v.13, n.3, p.604-618, 2012.
TILLEY, J.M.A.; TERRY, R.A. A twostage technique for the "in vitro" digestion of forage crops. Journal of British Grassland Society, v.18, n.2, p.104-111, 1963.

TOMICH, T.R.; LISITA, F.O.; MARAIS, M.G.; TOMICH, R.G.P.; FERREIRA, P.D.S.; GONÇALVES, L.C. Valor nutritivo de silagens de mandioca confeccionadas com diferentes frações da parte aérea de duas variedades de mandioca. Revista Brasileira de Agroecologia, v.3, n.1, p.198-201, 2008.

TOMICH, T.R.; NASCIMENTO, J.C.; TOMICH, R.G.P.; LISITA, F.O.; DOMINGOS BRANCO, O.; FEIDEN, A.; MORAIS, M.G. Feno da parte aérea da mandioca para a produção de ruminantes em sistemas orgânicos. Corumbá: Embrapa Pantanal. 2009. 10p.

VAN SOEST, P.J. Nutritional ecology of the ruminant. 2ed. Ithaca: Cornell University, 1994. 476p.

VAN SOEST, P.J.; ROBERTSON, J.B.; LEWIS, B.A. Methods for Dietary Fiber, Neutral Detergent Fiber, and Nonstarch Polysaccharides in Relation to Animal Nutrition. Journal of Dairy Science, v.74, n.10, p.3583-3597, 1991.

Data de recebimento: $15 / 10 / 2014$

Data de aprovação: 23/02/2016 